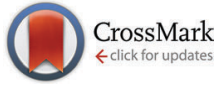

Cite this: Phys. Chem. Chem. Phys., $2014,16,26506$

Received 16th May 2014, Accepted 8th July 2014 DOI: $10.1039 / c 4 c p 02144 d$

www.rsc.org/pccp

\title{
Exploring the phase space of time of flight mass selected $\mathrm{Pt}_{x} \mathrm{Y}$ nanoparticles
}

\author{
Federico Masini, ${ }^{a}$ Patricia Hernández-Fernández, $\dagger^{\mathrm{a}}{ }^{\mathrm{D}}$ Davide Deiana, ${ }^{\mathrm{b}}$ \\ Christian Ejersbo Strebel, ${ }^{C}$ David Norman McCarthy, ${ }^{C}$ Anders Bodin, ${ }^{a}$ \\ Paolo Malacrida, ${ }^{a}$ Ifan Stephens ${ }^{a}$ and Ib Chorkendorff* ${ }^{a}$
}

\begin{abstract}
Mass-selected nanoparticles can be conveniently produced using magnetron sputtering and aggregation techniques. However, numerous pitfalls can compromise the quality of the samples, e.g. double or triple mass production, dendritic structure formation or unpredicted particle composition. We stress the importance of transmission electron microscopy (TEM), X-ray photoelectron spectroscopy (XPS) and ion scattering spectroscopy (ISS) for verifying the morphology, size distribution and chemical composition of the nanoparticles. Furthermore, we correlate the morphology and the composition of the $\mathrm{Pt}_{x} \mathrm{Y}$ nanoparticles with their catalytic properties for the oxygen reduction reaction. Finally, we propose a completely general diagnostic method, which allows us to minimize the occurrence of undesired masses.
\end{abstract}

\section{Introduction}

Heterogeneous catalysis of nanoparticles has been the subject of numerous investigations in recent years. ${ }^{1-15}$

Industrial catalysts are almost always in the nanoparticulate form due to their high surface area to volume ratio. Traditionally, the fundamental properties of catalysts were investigated on extended surfaces, e.g. single crystals. However, in recent years, an increasing number of model studies have been devoted to the direct investigation of nanoparticles. In some cases it turns out that the surface chemistry of nanoparticles is quite distinct from that of extended surfaces.

Size dependent effects have been observed in numerous catalytic systems such as those for Co nanoparticles in the Fischer-Tropsch reaction, where activity drops at particle sizes greater than 6-8 nm. ${ }^{16}$ Furthermore, Au nanoparticles showed a remarkably high activity for CO oxidation below $5 \mathrm{~nm}$ particle diameter, reaching a maximum in activity at $2-3 \mathrm{~nm}$ size. $^{17}$ Ruthenium has interesting catalytic properties for CO oxidation if prepared in the form of nanoparticles of diameter between $2 \mathrm{~nm}$ and $6 \mathrm{~nm}^{18}$

The reason for size dependence is still not entirely clear and has been debated for a long time. However, there are cases in which a combination of theoretical and experimental work has

\footnotetext{
${ }^{a}$ Center for Individual Particle Functionality (CINF), Department of Physics, DTU, DK-2800 Kgs. Lyngby, Denmark. E-mail: ibchork@fysik.dtu.dk

${ }^{b}$ Center for Electron Nanoscopy (CEN), Department of Physics, DTU, DK-2800 Kgs. Lyngby, Denmark

${ }^{c}$ Haldor Topsøe A/S, Nymøllevej 55, DK-2800 Kgs Lyngby, Denmark

$\dagger$ Present address: DanishTechnological Institute (DTI), Gregersensvej 1, DK-2630 Taastrup, Denmark.
}

elucidated the role of different types of sites in the catalytic activity, whose abundance is related to particle size and structure.

On the $\mathrm{Ru}(0001)$ surface, the so called $\mathrm{B}_{5}$ step sites were found to yield a much higher contribution to $\mathrm{N}_{2}$ dissociation (about nine orders of magnitude) than the facets. ${ }^{19}$ Recently, the same sites $\left(\mathrm{B}_{5}\right)$ were shown to have analogous properties in $\mathrm{Ru}$ nanoparticles, ${ }^{10}$ and the concentration of these sites has been correlated with particle size.

The relevance of surface steps and defects for catalytic purposes has been elucidated by the work of Vendelbo et al., ${ }^{20,21}$ who investigated the reactivity of the $\mathrm{Ru}(0154)$ surface $(\mathrm{Ru}(0001)$ with $4 \%$ steps) for methanation. Not only the steps proved to be of paramount importance for successful methane formation, but defects induced by sputtering readily improved the catalytic activity. Importantly, sulfur poisoning of the step sites reduced the catalytic activity, providing further evidence that all the catalytic properties are concentrated in the few defect sites.

A particularly illustrative example of where single crystal surfaces do not model the catalytic properties of nanoparticles can be found in the case of oxygen electroreduction. This reaction limits the efficiency of low temperature fuel cells, and prohibitively high loadings of Pt-based nanoparticles are required to catalyse the reaction. Most, albeit not all, theoretical and experimental studies seem to suggest that the surface specific activity for oxygen reduction should decrease with a decrease in particle size. ${ }^{12,22-28}$ However, this notion is in conflict with the experimental observation that extended single crystal stepped Pt surfaces sometimes exhibit higher oxygen reduction activity than unstepped surfaces. ${ }^{29-31}$

One strategy to improve the activity of Pt is to alloy it with other metals. Most research has been devoted to the study of 
alloys of $\mathrm{Pt}$ and late transition metals such as $\mathrm{Ni}, \mathrm{Co}, \mathrm{Cu}$ and $\mathrm{Fe}^{32-38}$ However, in the harsh acidic and oxidising environment of a fuel cell, these alloys degrade by dealloying. ${ }^{39-41}$ In our laboratory we have taken a different approach, namely to study alloys of $\mathrm{Pt}$ and rare earths such as Y, Gd, Ce and La. $^{33,42-48}$ These alloys have a particularly negative heat of formation, which should provide them with long term-kinetic stability against dealloying at the cathode of a fuel cell. Extended surfaces of $\mathrm{Pt}_{3} \mathrm{Y}$ and $\mathrm{Pt}_{5} \mathrm{Gd}$ show particularly high activity for oxygen reduction. ${ }^{42,43,47}$ On the other hand, upon exposure to reaction conditions, alloys such as $\mathrm{Pt}_{2} \mathrm{Y}$ or $\mathrm{PtY}$ corroded extensively, due to $\mathrm{Y}$ dissolution; this suggests that an excessive amount of $\mathrm{Y}$ is detrimental to catalyst stability. ${ }^{44}$ Most recently, we demonstrated that $\mathrm{Pt}_{x} \mathrm{Y}$ is also highly active for the oxygen reduction reaction in nanoparticulate form. The activity increases monotonically with particle size; we attributed this to an increased degree of compressive strain exerted by the alloy core onto the pure Pt shell. ${ }^{48}$

Importantly, size effects are not the only significant characteristics of nanoparticles. Improvements can be made to catalysts by forming non-equilibrium morphologies. ${ }^{14,38,49-53}$ Very recent results by Chen et al. $^{13}$ have shown unprecedented capabilities of $\mathrm{Pt}_{x} \mathrm{Ni}$ "nanoframes" to catalyze oxygen reduction.

It is of utmost importance to conduct studies on monodisperse, size selected nanoparticles, to be able to correlate size, shape and surface structure with the catalytic activity of the nanoparticles. Common problems which could arise are (i) too large particle size distribution, (ii) contaminations, (iii) polydispersity, (iv) undesired morphology e.g. dendritic shapes and (v) inadequate particle composition.

To circumvent the first and the second issues, we produce nanoparticles using a cluster source, ${ }^{54}$ interfaced with a von Issendorff (lateral time-of-flight) mass selector. ${ }^{55}$ The source produces particles with narrow size distribution by $\mathrm{Ar}^{+}$plasma sputtering followed by gas phase aggregation under ultra-clean conditions. Nonetheless, it is still necessary to avoid the last three problems to be able to study the catalytic properties of the deposited nanoparticles. To do so, greater attention must be paid to undesired higher mass production. Additionally, particular attention must be paid to the particle morphology and chemical composition.

These issues stress the necessity of checking the quality of the deposited samples, e.g. via transmission electron microscopy (TEM), X-ray photoelectron spectroscopy (XPS) and ion scattering spectroscopy (ISS).

In this paper, we show how different $\mathrm{Pt}_{x} \mathrm{Y}$ chemical composition affects the particle activity for ORR.

Furthermore, we discuss the conditions under which dendritic $\mathrm{Pt}_{x} \mathrm{Y}$ nanostructures are produced; we show that their electrochemical activity for ORR varies as a function of the morphology of the $\mathrm{Pt}_{x} \mathrm{Y}$ nanostructure.

Finally, we qualitatively correlate the quality of the deposited nanoparticle sample with the evolution in time of the deposition current versus mass curves, measured using a time of flight analyzer (TOF). We present a method to minimize the problem of multiple masses production, thereby greatly reducing the risk of compromising an experimental sample. Although the study is conducted on $\mathrm{Pt}_{x} \mathrm{Y}$ particles, the method is completely general.

\section{Experimental}

The $\mathrm{Pt}_{x} \mathrm{Y}$ nanoparticles were prepared using a magnetron sputter gas aggregation source (Birmingham Instruments Inc.), combined with a von Issendorff time-of-flight mass filter, and deposited onto Lacey Carbon-coated $\mathrm{Au}$ or $\mathrm{Si}_{3} \mathrm{~N}_{4}$ (for the $\mathrm{Ru}$ reference) TEM grids mounted in a multichamber ultrahigh vacuum (UHV) system (Omicron, Multiscan Lab) with a base pressure in the low $10^{-10}$ mbar region. The gas aggregation technique involves $\mathrm{Ar}^{+}$sputtering of a target (in this study $\mathrm{Ru}$ and Pt 9:1 Y, Pt 3:1 Y alloy targets from Kurt J. Lesker Inc.), to produce an atomic vapor that is condensed into nanoparticles through collisions with cooled Ar and He gas. The gas aggregation method is particularly useful in the context of formation of metallic nanoparticles from materials such as yttrium that have high affinities for oxygen, as it is an ultrahigh vacuum compatible method where oxygen is present at extremely low levels. The second chief advantage arises from the fact that a high fraction of the nanoparticles produced via $\mathrm{Ar}^{+}$sputtering are ionized, ${ }^{54}$ thus the particles can be filtered based on their mass-to-charge ratio, which in turn allows the deposition of particles with narrow size distributions. In our experiments the $\mathrm{Pt}-\mathrm{Y}$ and the $\mathrm{Ru}$ nanoparticles are filtered using a time-of-flight mass filter. ${ }^{55}$

Nanoparticle size distributions were obtained from TEM and high angle annular dark field (HAADF) STEM micrographs were acquired using a probe $\mathrm{C}_{\mathrm{s}}$-corrected FEI Titan Analytical 80-300 electron microscope operated at $300 \mathrm{kV}$ accelerating voltage.

The electrochemical experiments were performed using a Bio-Logic Instruments' VMP2 potentiostat, controlled by a computer. The rotating ring disk electrode (RRDE) assemblies and the glassy carbon substrates were provided by Pine Instruments Corporations. All glassware was cleaned in $96 \% \mathrm{H}_{2} \mathrm{SO}_{4}$ (Merck, Emsure) and 30\% $\mathrm{H}_{2} \mathrm{O}_{2}$ (Analar, Normpur) (3:1 v/v). Those were subsequently rinsed several times in hot Millipore water ( $85 \mathrm{C},>18.2 \mathrm{M} \Omega \mathrm{cm}^{-1}$, TOC $<5 \mathrm{ppb}$ ). A standard threecompartment glass cell was used for all the experiments, equipped with an external jacket attached to a water bath with temperature control. The electrolyte, $0.1 \mathrm{M} \mathrm{HClO}_{4}$ (Merck, Suprapur), was prepared using Millipore water. The counter electrode was a platinum wire and the reference was the $\mathrm{Hg} / \mathrm{Hg}_{2} \mathrm{SO}_{4}$ electrode separated from the working electrode compartment using a ceramic frit. The measurements were conducted at $23 \pm$ $1{ }^{\circ} \mathrm{C}$. All potentials in the manuscript are quoted with respect to the RHE and corrected for Ohmic losses. The catalyst prepared under UHV conditions was inserted into the arbor of a RRDE and was immersed into the electrochemical cell under potential control at $0.05 \mathrm{~V}$ in a $\mathrm{N}_{2}$ saturated $0.1 \mathrm{M} \mathrm{HClO}_{4}$ electrolyte. The potential was then constantly cycled between $0.05 \mathrm{~V}$ and $1.0 \mathrm{~V}$ until a stable cyclic voltammogram was recorded. The ORR 
activity was measured by cycling the potential between $0 \mathrm{~V}$ and $1 \mathrm{~V}$ at $50 \mathrm{mV} \mathrm{s}^{-1}$ and $1600 \mathrm{rpm}$, after saturating the solution in $\mathrm{O}_{2}$ (N55, AGA), whereas the stability tests were carried out by cycling the potential between $0.6 \mathrm{~V}$ and $1 \mathrm{~V}$ at $100 \mathrm{mV} \mathrm{s}^{-1}$ and $0 \mathrm{rpm}$ for 9000 potential cycles. The ORR specific activity, $\mathrm{mA} \mathrm{cm}_{\mathrm{Pt}}{ }^{-2}$, was calculated from the anodic sweep of the polarization curve. To that purpose, the kinetic current density, $j_{\mathrm{k}}$, for the ORR was calculated by using the following equation: $1 / j=1 / j_{\mathrm{k}}+1 / j_{\mathrm{d}}$, where $j$ is the measured current density and $j_{\mathrm{d}}$ is the diffusion limiting current density. The active surface area of each $\mathrm{Pt}_{x} \mathrm{Y}$ sample, $\mathrm{cm}_{\mathrm{Pt}}{ }^{2}$, was measured by $\mathrm{CO}$ stripping analyses, which were carried out in a CO-free Ar electrolyte at $50 \mathrm{mV} \mathrm{s}^{-1}$ after CO adsorption. The active surface area was estimated using the area under the CO-stripping peak assuming a charge of $420 \mu \mathrm{C} \mathrm{cm}{ }_{\mathrm{Pt}}{ }^{-2}$. 66

Low-energy ion scattering spectroscopy (ISS) was performed after deposition of the nanoparticles. A pressure of $5 \times$ $10^{-8}$ mbar of $\mathrm{He}$ was used for the analysis and a primary energy of $1000 \mathrm{eV}$ was used.

XPS measurements of the samples after electrochemical testing were taken on a Theta Probe instrument (Thermo Scientific). This instrument is equipped with a monochromatized $\mathrm{Al} \mathrm{K} \alpha(1486.7 \mathrm{eV})$ source, and XPS spectra were obtained with a pass energy of $100 \mathrm{eV}$. The analyzer has an acceptance angle of $60^{\circ}$, between $20^{\circ}$ and $80^{\circ}$ to the surface normal. An $\mathrm{X}$-ray beam size of $400 \mu \mathrm{m}$ was used for all measurements. The atomic concentrations were quantified by integration of the $\mathrm{Pt}$ 4f, Y 3d peaks after background removal. A Shirley-type background was chosen for this purpose. The intensities were corrected for the transmission function of the analyzer, relative sensitivity factors and the electron mean free path. The relative sensitivity factors of Pt and Y were experimentally determined, as described earlier, ${ }^{57}$ from the Pt $4 \mathrm{f}$ and $\mathrm{Y} 3 \mathrm{~d}$ spectra acquired after sputter-cleaning on a Pt(111) single crystal and Y foil, respectively.

\section{Results}

As mentioned in the Introduction, the electrochemical stability of polycrystalline $\mathrm{Pt}_{2} \mathrm{Y}$ and $\mathrm{PtY}$ was rather poor. Therefore, it was decided to decrease the yttrium content of the polycrystalline samples. Further electrocatalytic tests on the polycrystalline $\mathrm{Pt}_{3} \mathrm{Y}$ showed that this alloy is a stable catalyst for ORR.

$\mathrm{Pt}_{x} \mathrm{Y}$ nanoparticles were obtained by sputtering targets with decreasing yttrium content i.e. $\mathrm{Pt}_{3} \mathrm{Y}$ and $\mathrm{Pt}_{9} \mathrm{Y}$ targets.

The nanoparticles produced by sputtering the $\mathrm{Pt}_{3} \mathrm{Y}$ target were tested for ORR under the same conditions used for the nanoparticles obtained using the $\mathrm{Pt}_{9} \mathrm{Y}$ target. The ORR kinetic current densities at $0.9 \mathrm{~V}$ as a function of the particle size for the samples prepared with the $\mathrm{Pt}_{3} \mathrm{Y}$ target and the $\mathrm{Pt}_{9} \mathrm{Y}$ target are displayed in Fig. 1. The nanoparticles prepared from the $\mathrm{Pt}_{9} \mathrm{Y}$ target display a higher activity than the ones produced using the $\mathrm{Pt}_{3} \mathrm{Y}$ target. For instance, for the $5 \mathrm{~nm}$ case, the specific activity varies from $4.02 \mathrm{~mA} \mathrm{~cm}_{\mathrm{Pt}}{ }^{-2}$ to $2.25 \mathrm{~mA} \mathrm{~cm} \mathrm{Pt}^{-2}$. This great difference in activity is due to the difference in a

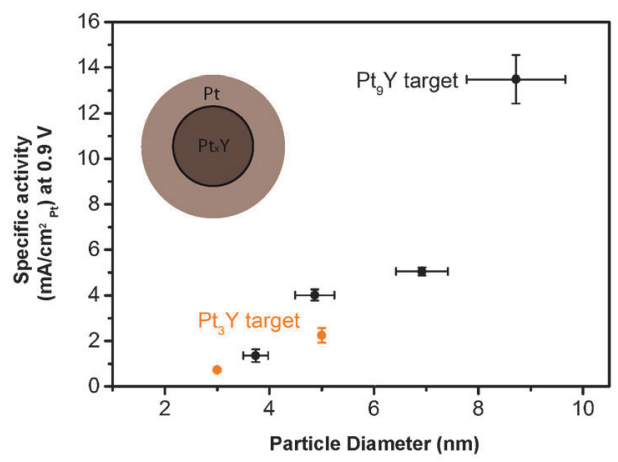

$b$

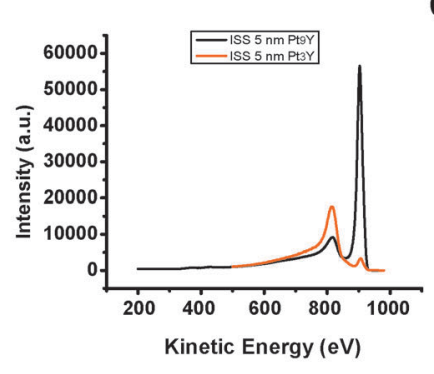

C

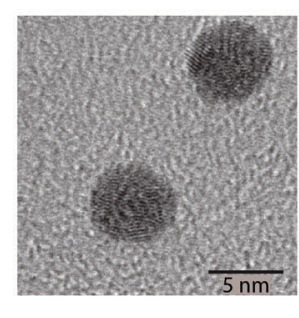

d

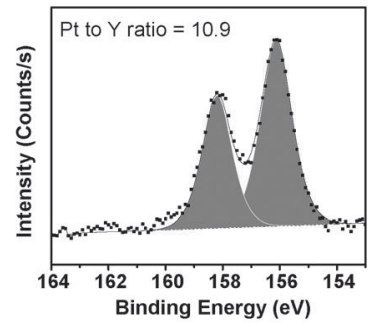

e

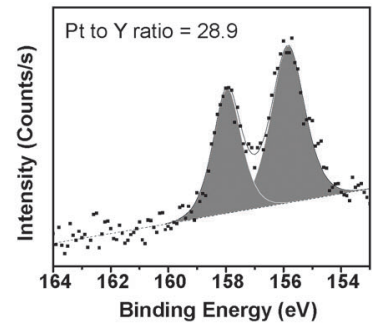

Fig. 1 (a) Specific activity at $0.9 \mathrm{~V}$ versus particle size for $\mathrm{Pt}_{x} \mathrm{Y}$ nanoparticles generated by sputtering two targets, $\mathrm{Pt}_{9} \mathrm{Y}$ (black) and $\mathrm{Pt}_{3} \mathrm{Y}$ (orange). The cartoon nanoparticle shows the formation of an overlayer of platinum on a $\mathrm{Pt}_{x} \mathrm{Y}$ core, as a consequence of $\mathrm{Y}$ leach-out during ORR. The electrochemical measurements were recorded at $50 \mathrm{mV} \mathrm{s}^{-1}, 1600 \mathrm{rpm}$ and $23 \pm 1{ }^{\circ} \mathrm{C}_{\text {in }} \mathrm{O}_{2}$-saturated $0.1 \mathrm{M} \mathrm{HClO}_{4}$ electrolyte. The current densities have been corrected for mass transport limitations. Each data point is the result of at least three independent measurements. The error bars show the standard deviation. (b) ISS spectra on $5 \mathrm{~nm}$ as-deposited particles produced from $\mathrm{Pt}_{3} \mathrm{Y}$ target (orange) and $\mathrm{Pt}_{9} \mathrm{Y}$ (black). The peak at $\sim 920 \mathrm{eV}$ is attributed to $\mathrm{Pt}$, whereas the peak at $\sim 800 \mathrm{eV}$ is attributed to $\mathrm{Y}$. (c) Representative TEM image of the nanoparticles obtained by sputtering the $\mathrm{Pt}_{3} \mathrm{Y}$ target. XPS spectra of the $Y 3 d$ core level region for $10 \mathrm{~nm}$ NPs after ORR (the peaks are attributed to metallic yttrium), obtained from (d) $\mathrm{Pt}_{3} \mathrm{Y}$ target and (e) $\mathrm{Pt}_{9} \mathrm{Y}$ target. The $\mathrm{Pt} / \mathrm{Y}$ ratio is reported for each spectrum.

nanoparticle surface composition ( $\mathrm{Pt} / \mathrm{Y}$ ratio), as demonstrated in Fig. 1b, where the ion scattering spectroscopy (ISS), taken on the as deposited particles, are shown for both samples. The ISS spectrum of the $\mathrm{Pt}_{9} \mathrm{Y}$ target has an atomic $\mathrm{Pt} / \mathrm{Y}$ ratio of 2.5 , substantially higher than 0.11 for the $\mathrm{Pt}_{3} \mathrm{Y}$ target. TEM (Fig. 1d) shows that the particles obtained from the $\mathrm{Pt}_{3} \mathrm{Y}$ target are spherical as for the nanoparticles (NPs) obtained sputtering the $\mathrm{Pt}_{9} \mathrm{Y}$ target (shown in Fig. 3). This is not surprising: the sputtering conditions for the $\mathrm{Pt}_{3} \mathrm{Y}$ target were similar to the sputtering conditions for the $\mathrm{Pt}_{9} \mathrm{Y}$ target, and the two targets have similar densities. 
a

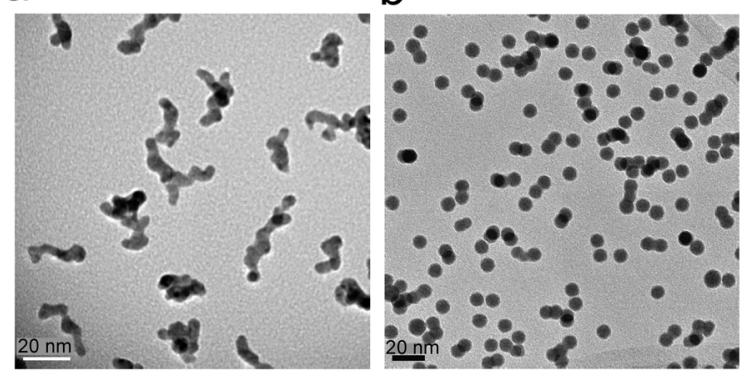

C

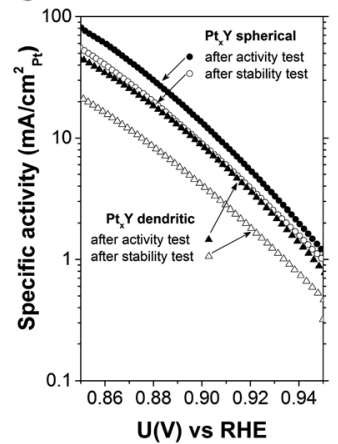

Fig. 2 Representative TEM images of dendritic (a) and spherical (b) nanoparticles obtained by sputtering a Ptg $\mathrm{Y}$ target at high and low rates, respectively. (c) ORR Tafel plots for the $\mathrm{Pt}_{x} \mathrm{Y}$ dendritic and spherical nanoparticles after activity test (black triangles and circles, respectively). The Tafel plots after 9000 potential cycles are also shown (white triangles and circles, respectively). The electrochemical measurements were recorded at $50 \mathrm{mV} \mathrm{s}{ }^{-1}, 1600 \mathrm{rpm}$ and $23 \pm 1{ }^{\circ} \mathrm{C}$ in $\mathrm{O}_{2}$-saturated $0.1 \mathrm{M} \mathrm{HClO}_{4}$ electrolyte. The current densities have been corrected for mass transport limitations.

Fig. 1d and e show the XPS spectra of the Y3d core level region after ORR for $10 \mathrm{~nm}$ nanoparticles. The nanoparticles were fabricated from $\mathrm{Pt}_{3} \mathrm{Y}$ and $\mathrm{Pt}_{9} \mathrm{Y}$ targets, respectively. The $\mathrm{Pt} / \mathrm{Y}$ ratios, displayed in the corresponding spectra, are 10.9 and 28.9 , respectively.

The chemical composition of the sample is not the only issue which deserves attention when preparing a sample. Morphology also matters.

Fig. 2 displays representative TEM images of two $9 \mathrm{~nm} \mathrm{Pt}_{x} \mathrm{Y}$ nanoparticulate samples displaying different morphologies. In one image, Fig. 2a, the particles have dendritic morphology, whereas in the other image, Fig. $2 \mathrm{~b}$, the particles are spherical. The conditions under which the particles were prepared were very different. In the case of the dendritic particles, $70 \mathrm{~W}$ and a flow of Ar of $120 \mathrm{ml} \mathrm{min}^{-1}$ and $\mathrm{He}$ of $20 \mathrm{ml} \mathrm{min}^{-1}$ were used. The selected particles were positively charged. In the case of the spherical particles, $9 \mathrm{~W}$ and an Ar flow of $30 \mathrm{ml} \mathrm{min}^{-1}$ were used. The particles were negatively charged.

The specific activity after ORR and stability studies as a function of the applied potential for both dendritic and spherical $\mathrm{Pt}_{x} \mathrm{Y}$ particles are shown in Fig. 2c. The two morphologies present dramatically different activities and corrosion resistance. The initial ORR specific activity at $0.9 \mathrm{~V}$ is $c a .13 .5 \mathrm{~mA} \mathrm{~cm}_{\mathrm{Pt}^{-2}}$ for the spherical nanoparticles, while for the dendritic ones it decreases to $8.7 \mathrm{~mA} \mathrm{~cm}{ }_{\mathrm{Pt}}{ }^{-2}$. Not only is the activity, but also the stability influenced by the shape of the particles. Spherical particles only lose around $35 \pm 5 \%$ of their activity after 9000 potential cycles. Dendritic particles lose around $60 \pm 10 \%$ of their initial activity.

The first requirement for correct size-selection is the monodispersion of the nanoparticles. Using magnetron sputtering techniques, one typically scans a large range of masses to determine the distribution of masses that exit the sputtering chamber. Fig. 3 shows the particle size distribution (PSD) and a TEM image of a $\mathrm{Pt}_{x} \mathrm{Y}$ sample, where the peak intensity was intended to be $9 \mathrm{~nm}$. It appears obvious that the deposition of monodispersed nanoparticles failed, since the PSD is trimodal and peaked at $8.75 \mathrm{~nm}, 11.2 \mathrm{~nm}$ and $13 \mathrm{~nm}$.
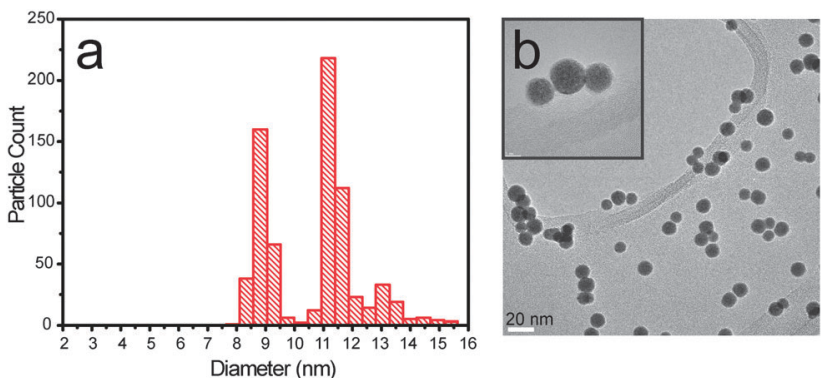

Fig. 3 (a) Particle size distribution for a $9 \mathrm{~nm} \mathrm{Pt} t_{x}$ deposition and (b) bright field TEM image. In the inset (top left corner) three particles are magnified to show the presence of undesired double and triple mass particles.

Fig. 4a shows two deposition curves for $\mathrm{Pt}_{x} \mathrm{Y} 7 \mathrm{~nm}$. In this case, a shift in the deposition curve minima was detected (from 2 million amu to 1.6 million amu) and some change in the shape of the deposition curves is noticeable.

A deposition curve is a mass distribution which is recorded before and after the deposition; before the deposition we select a target mass, $M$, which is kept fixed throughout the deposition.

As the deposition is completed, the features of the profile appear less smeared out, compared to the starting deposition curve. Nonetheless, the qualitative aspect of the curve is preserved. Furthermore, after deposition, an increase in the $M / 2 M$ ratio was observed; the $M / 2 M$ ratio shifts from 0.76 to 4.75 .

A fraction of undesired particles, $c a$. $20 \%$, is observed in both the particle size distribution and TEM micrograph displayed in Fig. $2 \mathrm{c}$ for the $\mathrm{Pt}_{x} \mathrm{Y} 7 \mathrm{~nm}$ sample. The intended size was $\sim 7 \mathrm{~nm}$.

As a reference for an ideal deposition we show, in Fig. 4d, two current versus mass curves for the Ru nanoparticle. In red, the current versus mass curve taken before the deposition is shown, and in blue the current versus mass curve collected after the deposition is shown. The curves do not vary significantly. The starting value of the $M / 2 M$ ratio is 24 , where $M$ is the selected mass, and the $M / 2 M$ ratio slightly increases throughout the deposition. The corresponding PSD and TEM shown in 

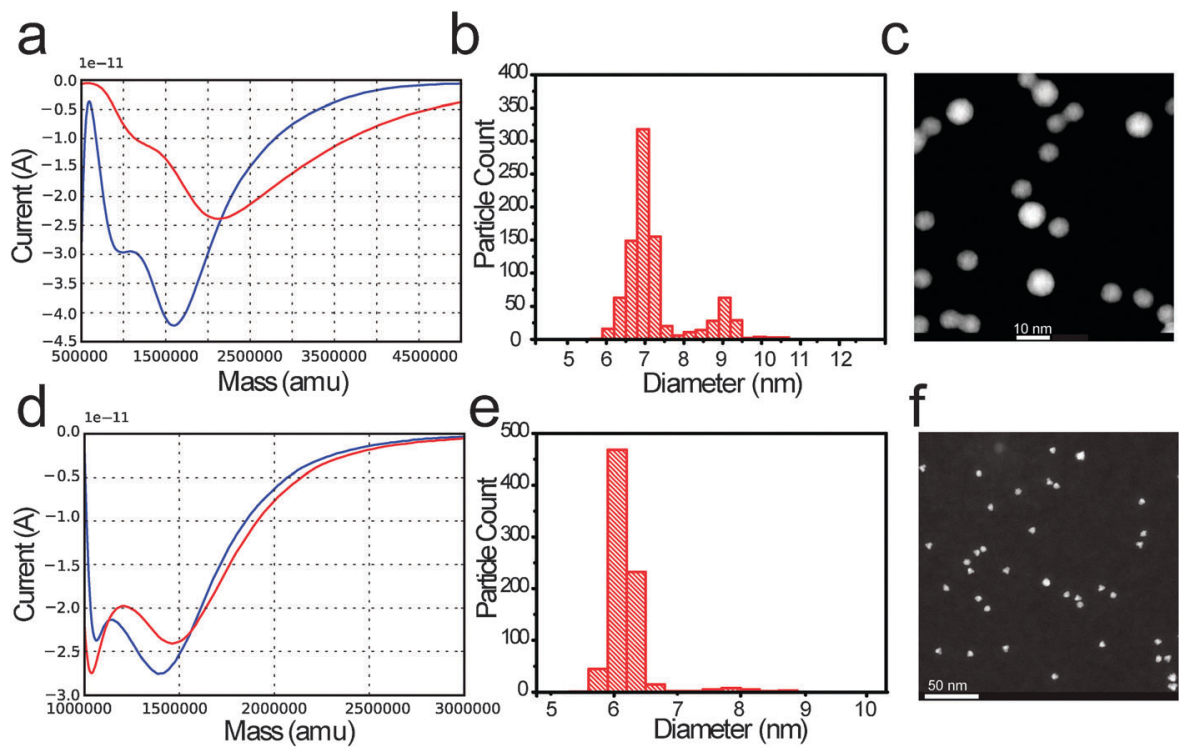

Fig. 4 (a) Current versus mass curve (measured with TOF mass selector) before (red curve) and after (blue curve) Pt $t_{x}$ Y NPs deposition. (b) Corresponding particle size distribution and (c) representative dark field STEM image relative to the deposited sample. The intended size was $7 \mathrm{~nm}$. As an ideal deposition reference: (d) current versus mass curve (measured with TOF mass selector) before (red curve) and after (blue curve) Ru NPs deposition. (e) Corresponding particle size distribution and (f) representative dark field STEM image relative to the deposited sample. The intended size was $7 \mathrm{~nm}$.

Fig. $4 \mathrm{e}$ and $\mathrm{f}$ indicate a very little amount of undesired mass (about $4 \%$ ) at $\sim 7.8 \mathrm{~nm}$.

\section{Discussion}

In the first part of the "Results" section, we presented a case which highlights the dependence of the nanoparticle composition on the composition of the sputtering target. The ISS spectra confirm that, at least on the surface, the nanoparticles produced from the $\mathrm{Pt}_{3} \mathrm{Y}$ are richer in $\mathrm{Y}$ than the ones prepared from the $\mathrm{Pt}_{9} \mathrm{Y}$ target. Furthermore, under the assumption that the composition of the $\mathrm{Pt}_{x} \mathrm{Y}$ alloy is uniform throughout the particle, ${ }^{48}$ XPS after ORR show that the NPs produced from the $\mathrm{Pt}_{3} \mathrm{Y}$ target are richer in $\mathrm{Y}$ than the NPs produced from the $\mathrm{Pt}_{9} \mathrm{Y}$. This is similar to what was observed by Gan et al. in an earlier study on $\mathrm{Pt}_{x} \mathrm{Ni}$ nanoparticles. ${ }^{58}$

As we proposed recently, ${ }^{48}$ the presence of $\mathrm{Y}$ in the $\mathrm{Pt}$ lattice induces a compressive surface strain in the Pt overlayer of the NP (Fig. 1a), destabilising OH intermediates of the ORR. However, a Pt/Y ratio different from the optimum one might change the amount of the binding energy shift, resulting in a less efficient catalyst.

Besides particle chemical composition, other parameters must be kept under control. In Fig. 2 we displayed two entirely different morphologies of $\mathrm{Pt}_{x} \mathrm{Y}$ nanoparticles obtained by sputtering a $\mathrm{Pt}_{9} \mathrm{Y}$ target. The conditions of operation were totally different, though. To produce dendritic nanoparticles both the Ar flux and the power employed were around five times to one order of magnitude higher than those required to produce spherical nanoparticles. This provided a much higher rate of sputtering for the dendritic case than for the spherical case, which resulted in a higher rate of aggregation, as discussed by Alayan et $a .^{59}$
Importantly, these high sputtering rate conditions are imposed by the choice of positive particle deposition for the dendritic case. Negative particle deposition requires substantially lower sputtering rate, and therefore results in spherical particle production, rather than dendrite formation.

Different morphologies showed different reactivity in the electro-reduction of oxygen and also different corrosion resistance, with the spherical particles losing about a half in activity compared to the dendritic particles. Tentatively, the reduced corrosion resistance for the dendritic nanoparticles might be ascribed to easier diffusion of yttrium out of the dendritic nanostructures. Furthermore, the dendritic structure might modify the extent of the Pt lattice strain, thereby affecting the activity.

Besides morphology and chemical composition of the particle, one should also concentrate on monodispersion. The peaks in the trimodal distribution showed in Fig. 3 are located at particle diameters which have ratios of $(11.2 / 8.75)=1.28$ and $(13 / 8.75)=1.48$, respectively. These values are remarkably close, within the error bar, to the cube root of $2(\sim 1.26)$, and to the cube root of $3(\sim 1.45)$. This suggests that particles with mass double or triple of the intended mass were also deposited. TEM images shown in Fig. 3 and 4 confirm that double or triple mass particles were deposited.

This is a serious problem which can occur while depositing clusters and nanoparticles synthesized using sputtering and aggregation techniques. The presence of significant amounts of nanoparticles with double or triple masses may completely compromise the result of a catalytic experiment.

Masses are effectively filtered through a Von Issendorff type Time of Flight (TOF) mass filter, however, the chance for the deposition of undesired masses is not zero. Masses which are multiples according to an integer $n$ of the intended mass $M$ can 
also be filtered; all that is needed is that their charge $e$ is a multiple according to the same integer $n$, so that the mass to charge ratio is equal to the desired one. The relevant quantity here is the mass to charge ratio: $\frac{n M}{n e}$.

The presence of multiple negative charges (particularly with $n<4$ ) is not unlikely for nanoparticles with diameter in the range 1-10 $\mathrm{nm}$. This is due to the presence of a Coulomb barrier inhibiting the loss of electrons, as discussed by other authors. ${ }^{60,61}$ However, it seems that charges higher than $3 e$ do not represent a serious threat for the deposition. This is corroborated by the fact that, in Fig. 3, the quadruple mass peak at $9 \times 1.59=14.3 \mathrm{~nm}$ is really negligible compared to the other peaks.

Nanoparticles with a charge higher than $3 e$ would probably rapidly discharge through the electron tunnelling mechanism. However, double $(n=2)$ or even triple negative charges $(n=3)$ can be retained by the nanoparticle for time intervals long enough to represent a serious problem in the particle mass selection process.

The case presented in Fig. $4 \mathrm{a}-\mathrm{c}$ represents an acceptable case of deposition.

The deposition starts at $0.76 \mathrm{M} / 2 \mathrm{M}$. This would be a disastrous ratio to start with, and a majority of $2 M$ should be deposited. However, the ratio changes during the deposition, and the final ratio is 4.75 . This prevents a large quantity of $2 M$ from passing through the mass filter.

The reference case presented in Fig. $4 \mathrm{~d}-\mathrm{f}$ represents the ideal case of deposition. The $M / 2 M$ ratio is very high $(>20)$ compared to Fig. 4a, and remains high throughout the deposition. As a consequence, very few $2 M$ are filtered through the time of flight analyzer. The particles filtered are of a different element (Ru) compared to the ones shown in Fig. 4a-c, to stress the generality of the concept.

In summary, great care should be taken in choosing deposition profiles (deposition current versus deposited mass curves) which present an $M / 2 M$ ratio as high as possible. The outcome of the deposition should be checked at the end of the deposition, to ensure that such a ratio has not changed significantly, compared to the starting curve.

Deposition curves offer a fast and reliable diagnostic method to ensure that the deposition was performed correctly.

If the ratio of $M / 2 M$ stays at high values ( $>20$ at least) throughout the deposition, one can be confident the amount of multiple masses will be minimized. This threshold value is expected to vary with particle size, resulting in larger particles (diameter $>5 \mathrm{~nm}$ ) being the most exposed to this kind of problem.

To achieve a high $M / 2 M$ ratio, two phenomena should be avoided: (i) the shift of deposition minima and (ii) the appearance of new minima, compared to the pre-deposition curves. These two phenomena can mar the deposition outcome by changing the $M / 2 M$ ratio beyond the allowed threshold.

Interestingly, we have noticed that in the cluster source we use, a potentially dangerous shift in the deposition minimum can occur as a result of a variation in pressure in the aggregation chamber. In Fig. 5b, three deposition curves taken at 15 minutes
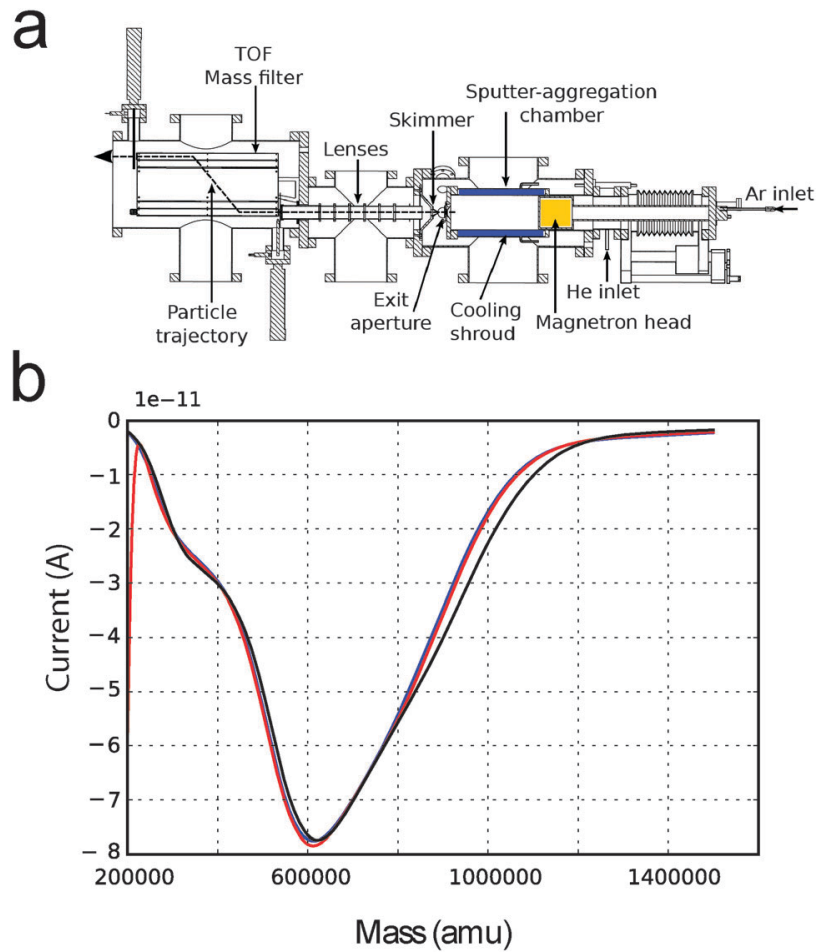

Fig. 5 (a) Scheme of the Birmingham cluster source used to deposit size selected nanoparticles. (b) Current versus mass deposition curves taken keeping the pressure in the sputter-aggregation chamber constant. The three deposition curves were collected at time intervals of 15 minutes.

time from each other are shown. In this case, the pressure at the "Exit Aperture" (Fig. 5a) was kept constant by regulating the flow of He/Ar sputter gas with a feedback loop. The deposition curves show no significant change over a time that is comparable with a typical deposition time. Therefore, we can conclude that by keeping the pressure constant, depositions which are more reliable can be achieved.

We note that the double or triple mass problem presented here might be, in rare cases, caused by other factors such as sudden changes in the plasma state or abrupt change in the temperature of the sputter-aggregation chamber.

\section{Conclusions}

Using the magnetron sputtering and gas aggregation technique, we have shown how composition and morphology influence the catalytic activity of $\mathrm{Pt}_{x} \mathrm{Y}$ nanoparticles. The interplay between microscopic, spectroscopic techniques and nanoparticle production is of paramount importance, if the catalytic properties of nanoparticles are to be correctly understood and predicted.

We have analysed the deposition curves (deposition current versus deposited mass) for size-selected nanoparticles produced using magnetron sputtering techniques. We proposed a simple protocol to gain feedback regarding whether the depositions contain negligible or intolerable amounts of double/triple mass. Although here we have focussed on $\mathrm{Pt}_{x} \mathrm{Y}$ nanoparticles, 
our approach is general and could be applied to any particle produced using this method.

\section{Acknowledgements}

The authors gratefully acknowledge financial support from the Danish Ministry of Science's UNIK initiative, Catalysis for Sustainable Energy. The Center for Individual Nanoparticle Functionality is supported by the Danish National Research Foundation (DNRF54). The A. P. Møller and Chastine Mc-Kinney Møller Foundation is gratefully acknowledged for its contribution towards the establishment of the Centre for Electron Nanoscopy in the Technical University of Denmark. The Interdisciplinary Centre for Electron Microscopy (CIME) at EPFL is gratefully acknowledged for the use of the FEI Tecnai Osiris TEM. Support for this work was received from the Danish Council for Strategic Research's project NACORR (12-133817) and MEDLYS (10-093906). I.E.L.S. was supported by the ForskEL programme's project CATBOOSTER (2001-1-10669). D.N.M. is the recipient of a HC Ørsted postdoctoral fellowship.

\section{References}

1 S. Vajda, M. J. Pellin, J. P. Greeley, C. L. Marshall, L. A. Curtiss, G. A. Ballentine, J. W. Elam, S. Catillon-Mucherie, P. C. Redfern, F. Mehmood and P. Zapol, Nat. Mater., 2009, 8, 213-216.

2 Y. Lei, F. Mehmood, S. Lee, J. Greeley, B. Lee, S. Seifert, R. E. Winans, J. W. Elam, R. J. Meyer, P. C. Redfern, D. Teschner, R. Schlögl, M. J. Pellin, L. A. Curtiss and S. Vajda, Science, 2010, 328, 224-228.

3 J. A. van Bokhoven, C. Louis, J. T. Miller, M. Tromp, O. V. Safonova and P. Glatzel, Angew. Chem., Int. Ed., 2006, 45, 4651-4654.

4 J. T. Miller, A. J. Kropf, Y. Zha, J. R. Regalbuto, L. Delannoy, C. Louis, E. Bus and J. A. van Bokhoven, J. Catal., 2006, 240, 222-234.

5 A. Tuxen, S. Carenco, M. Chintapalli, C.-H. Chuang, C. Escudero, E. Pach, P. Jiang, F. Borondics, B. Beberwyck, A. P. Alivisatos, G. Thornton, W.-F. Pong, J. Guo, R. Perez, F. Besenbacher and M. Salmeron, J. Am. Chem. Soc., 2013, 135, 2273-2278.

6 H. M. Torres Galvis, J. H. Bitter, C. B. Khare, M. Ruitenbeek, A. I. Dugulan and K. P. de Jong, Science, 2012, 335, 835-838.

7 G. Prieto, J. Zečević, H. Friedrich, K. P. de Jong and P. E. de Jongh, Nat. Mater., 2013, 303, 31-40.

8 M. Nesselberger, M. Roefzaad, R. Faysal Hamou, P. Ulrich Biedermann, F. F. Schweinberger, S. Kunz, K. Schloegl, G. K. H. Wiberg, S. Ashton, U. Heiz, K. J. J. Mayrhofer and M. Arenz, Nat. Mater., 2013, 3712, 1-6.

9 S. Kunz, K. Hartl, M. Nesselberger, F. F. Schweinberger, G. Kwon, M. Hanzlik, K. J. J. Mayrhofer, U. Heiz and M. Arenz, Phys. Chem. Chem. Phys., 2010, 12, 10288-10291.

10 J. Gavnholt and J. Schiøtz, Phys. Rev. B: Condens. Matter Mater. Phys., 2008, 77, 035404.
11 F. Masini, C. E. Strebel, D. N. McCarthy, A. U. F. Nierhoff, J. Kehres, E. M. Fiordaliso, J. H. Nielsen and I. Chorkendorff, J. Catal., 2013, 308, 282-290.

12 F. J. Perez-Alonso, D. N. McCarthy, A. Nierhoff, P. HernandezFernandez, C. Strebel, I. E. L. Stephens, J. H. Nielsen and I. Chorkendorff, Angew. Chem., Int. Ed., 2012, 51, 4641-4643.

13 C. Chen, Y. Kang, Z. Huo, Z. Zhu, W. Huang, H. L. Xin, J. D. Snyder, D. Li, J. A. Herron, M. Mavrikakis, M. Chi, K. L. More, Y. Li, N. M. Markovic, G. A. Somorjai, P. Yang and V. R. Stamenkovic, Science, 2014, 343, 1339-1343.

14 S. Mostafa, F. Behafarid, J. R. Croy, L. K. Ono, L. Li, J. C. Yang, A. I. Frenkel and B. R. Cuenya, J. Am. Chem. Soc., 2010, 132, 15714-15719.

15 F. Behafarid, L. K. Ono, S. Mostafa, J. R. Croy, G. Shafai, S. Hong, T. S. Rahman, S. R. Bareb and B. Roldan Cuenya, Phys. Chem. Chem. Phys., 2012, 14, 11766-11779.

16 G. L. Bezemer, J. H. Bitter, H. P. C. E. Kuipers, H. Oosterbeek, J. E. Holewijn, X. Xu, F. Kapteijn, A. J. van Dillen and K. P. de Jong, J. Am. Chem. Soc., 2006, 128, 3956-3964.

17 M. Haruta, Catal. Today, 1997, 36, 153-166.

18 S. H. Joo, J. Y. Park, J. R. Renzas, D. R. Butcher, W. Huang and G. A. Somorjai, Nano Lett., 2010, 10, 2709-2713.

19 S. Dahl, A. Logadottir, R. C. Egeberg, J. H. Larsen, I. Chorkendorff, E. Törnqvist and J. K. Nørskov, Phys. Rev. Lett., 1999, 83, 1814-1817.

20 S. B. Vendelbo, M. Johansson, J. H. Nielsen and I. Chorkendorff, Phys. Chem. Chem. Phys., 2011, 13, 4486-4493.

21 S. B. Vendelbo, M. Johansson, D. J. Mowbray, M. P. Andersson, F. Abild-Pedersen, J. H. Nielsen, J. K. Nørskov and I. Chorkendorff, Top. Catal., 2010, 53, 357-364.

22 H. A. Gasteiger, S. S. Kocha, B. Sompalli and F. T. Wagner, Appl. Catal., B, 2005, 56, 9-35.

23 K. J. J. Mayrhofer, D. Strmcnik, B. B. Blizanac, V. Stamenkovic, M. Arenz and N. M. Markovic, Electrochim. Acta, 2008, 53, 3181-3188.

24 S. W. Lee, S. Chen, W. Sheng, N. Yabuuchi, Y.-T. Kim, T. Mitani, E. Vescovo and Y. Shao-Horn, J. Am. Chem. Soc., 2009, 131, 15669-15677.

25 J. P. Greeley, J. Rossmeisl, A. Hellman and J. K. Nørskov, Z. Phys. Chem., 2007, 221, 1209-1220.

26 G. A. Tritsaris, J. Greeley, J. Rossmeisl and J. K. Nørskov, Catal. Lett., 2011, 141, 909-913.

27 M. Nesselberger, S. Ashton, J. C. Meier, I. Katsounaros, K. J. J. Mayrhofer and M. Arenz, J. Am. Chem. Soc., 2011, 133, 17428-17433.

28 W. Sheng, S. Chen, E. Vescovo and Y. Shao-Horn, J. Electrochem. Soc., 2012, 159, B96-B103.

29 A. Kuzume, E. Herrero and J. M. Feliu, J. Electroanal. Chem., 2007, 599, 333-343.

30 A. Hitotsuyanagi, M. Nakamura and N. Hoshi, Electrochim. Acta, 2012, 82, 512-516.

31 A. S. Bandarenka, H. A. Hansen, J. Rossmeisl and I. E. L. Stephens, Phys. Chem. Chem. Phys., 2014, 16, 13625-13629.

32 H. A. Gasteiger and N. M. Markovic, Science, 2009, 324, 48-49.

33 I. E. L. Stephens, A. S. Bondarenko, U. Grønbjerg, J. Rossmeisl and I. Chorkendorff, Energy Environ. Sci., 2012, 5, 6744-6762. 
34 T. Toda, H. Igarashi, H. Uchida and M. Watanabe, J. Electrochem. Soc., 1999, 146, 3750-3756.

35 V. R. Stamenkovic, B. Fowler, B. S. Mun, G. Wang, P. N. Ross, C. A. Lucas and N. M. Markovic, Science, 2007, 315, 493-497.

36 V. R. Stamenkovic, B. S. Mun, M. Arenz, K. J. J. Mayrhofer, C. A. Lucas, G. Wang, P. N. Ross and N. M. Markovic, Nat. Mater., 2007, 6, 241-247.

37 D. L. Wang, H. L. L. Xin, R. Hovden, H. S. Wang, Y. C. Yu, D. A. Muller, F. J. DiSalvo and H. D. Abruna, Nat. Mater., 2013, 12, 81-87.

38 C. H. Cui, L. Gan, M. Heggen, S. Rudi and P. Strasser, Nat. Mater., 2013, 12, 765-771.

39 H. L. Xin, J. A. Mundy, Z. Liu, R. Cabezas, R. Hovden, L. F. Kourkoutis, J. Zhang, N. P. Subramanian, R. Makharia, F. T. Wagner and D. A. Muller, Nano Lett., 2011, 12, 490-497.

40 S. Chen, H. A. Gasteiger, K. Hayakawa, T. Tada and Y. ShaoHorn, J. Electrochem. Soc., 2010, 157, A82-A97.

41 L. Dubau, F. Maillard, M. Chatenet, J. André and E. Rossinot, Electrochim. Acta, 2010, 56, 776-783.

42 J. Greeley, I. E. L. Stephens, A. S. Bondarenko, T. P. Johansson, H. A. Hansen, T. F. Jaramillo, J. Rossmeisl, I. Chorkendorff and J. K. Nørskov, Nat. Chem., 2009, 1, 552-556.

43 M. Escudero-Escribano, A. Verdaguer-Casadevall, P. Malacrida, U. Grønbjerg, B. P. Knudsen, A. K. Jepsen, J. Rossmeisl, I. E. L. Stephens and I. Chorkendorff, J. Am. Chem. Soc., 2012, 134, 16476-16479.

44 I. E. L. Stephens, A. S. Bondarenko, L. Bech and I. Chorkendorff, ChemCatChem, 2012, 4, 341-349.

45 T. P. Johansson, E. T. Ulrikkeholm, P. Hernandez-Fernandez, P. Malacrida, H. A. Hansen, A. S. Bandarenka, J. K. Nørskov, J. Rossmeisl, I. E. L. Stephens and I. Chorkendorff, Top. Catal., 2014, 57, 245-254.

46 P. Malacrida, M. Escudero-Escribano, A. VerdaguerCasadevall, I. E. L. Stephens and I. Chorkendorff, J. Mater. Chem. A, 2014, 2, 4234-4243.

47 T. P. Johansson, E. T. Ulrikkeholm, P. Hernandez-Fernandez, M. Escudero-Escribano, P. Malacrida, I. E. L. Stephens and
I. Chorkendorff, Phys. Chem. Chem. Phys., 2014, 16, 13718-13725.

48 P. Hernandez-Fernandez, F. Masini, D. N. McCarthy, C. E. Strebel, D. Friebel, D. Deiana, P. Malacrida, A. Nierhoff, A. Bodin, A. M. Wise, J. H. Nielsen, T. W. Hansen, A. Nilsson, I. E. L. Stephens and I. Chorkendorff, Nat. Chem., 2014, DOI: 10.1038/nchem.2001.

49 V. Komanicky, H. Iddir, K.-C. Chang, A. Menzel, G. Karapetrov, D. Hennessy, P. Zapol and H. You, J. Am. Chem. Soc., 2009, 131, 5732-5733.

50 C. Wang, H. Daimon, T. Onodera, T. Koda and S. Sun, Angew. Chem., Int. Ed., 2008, 47, 3588-3591.

51 J. Wu, J. Zhang, Z. Peng, S. Yang, F. T. Wagner and H. Yang, J. Am. Chem. Soc., 2010, 132, 4984-4985.

52 J. X. Wang, C. Ma, Y. Choi, D. Su, Y. Zhu, P. Liu, R. Si, M. B. Vukmirovic, Y. Zhang and R. R. Adzic, J. Am. Chem. Soc., 2011, 133, 13551-13557.

53 L. Dubau, M. Lopez-Haro, L. Castanheira, J. Durst, M. Chatenet, P. Bayle-Guillemaud, L. Guétaz, N. Caqué, E. Rossinot and F. Maillard, Appl. Catal., B, 2013, 142-143, 801-808.

54 H. Haberland, M. Karrais, M. Mall and Y. Thurner, J. Vac. Sci. Technol., A, 1992, 10, 3266-3271.

55 B. von Issendorff and R. E. Palmer, Rev. Sci. Instrum., 1999, 70, 4497-4501.

56 F. Maillard, E. R. Savinova and U. Stimming, J. Electroanal. Chem., 2007, 599, 221-232.

57 M. P. S. D. Briggs, Practical Surface Analysis, Auger and X-ray Photoelectron Spectroscopy, 1996.

58 L. Gan, M. Heggen, S. Rudi and P. Strasser, Nano Lett., 2012, 12, 5423-5430.

59 R. Alayan, L. Arnaud, M. Broyer, E. Cottancin, J. Lermé, J. L. Vialle and M. Pellarin, Phys. Rev. B: Condens. Matter Mater. Phys., 2006, 73, 125444.

60 R. N. Compton, A. A. Tuinman, C. E. Klots, M. R. Pederson and D. C. Patton, Phys. Rev. Lett., 1997, 78, 4367-4370.

61 C. Yannouleas and U. Landman, Chem. Phys. Lett., 1994, 217, 175-185. 